\title{
Micropropagation of an important medicinal herb Eclipta alba (L.) Hassk.
}

\author{
S. Yesmin ${ }^{*}$, A. Hashem and M. S. Islam ${ }^{1}$ \\ National Institute of Biotechnology, Ganakbari, Savar, Dhaka-1349, Bangladesh
}

\begin{abstract}
Nodal segments from naturally grown Eclipta alba (L.) Hassk.were used as explants for organogenesis. Multiple shoots were obtained from the explants cultured on MS medium supplemented with various concentrations of BAP and $\mathrm{Kn}$ alone or in combination with NAA and IAA. Maximum number of multiple shoots (18.40 \pm 0.67$)$ were induced on MS medium supplemented with $1.0 \mathrm{mg} / \mathrm{B} \mathrm{BAP}$ and $0.1 \mathrm{mg} / \mathrm{NAA}$. In vitro raised shoots were cultured onto half and full strength MS medium supplemented with different concentration of IBA, IAA and NAA. The best root induction medium was found to be half strength MS containing $0.1 \mathrm{mg} / \mathrm{IBA}$ where $96 \%$ shoots rooted. Regenerated plantlets grew normally without showing any morphological variation and flowered after 45 days of transplantation.
\end{abstract}

Key words: Eclipta alba, nodal explant, Micropropagation, In vitro, acclimatization

\section{INTRODUCTION}

Eclipta alba (L.) Hassk. is a small branched herb with white flower heads belonging to the family Asteraceae. This species grows commonly in moist places as a weed. In Bangladesh this plant grows in rainy season in paddy field and all over the country. Commercial exploitation and elimination of natural habits consequent of urbanization has led to gradual extinction of several medicinal plants (Hassan et. al., 2008). Its natural growth is discreet and on in limited period and specific land types. Due to its inconsistent natural growth it is difficult to harvest as well as preserve seed for large or commercial cultivation. Micropopagation techniques could solve these problems.

Eclipta alba (L.) Hassk. contains wide range of active principles which include coumestans, alkaloids, flavonoids, glycosides, polyacetylenes, tri-terpenoids. The leaves, roots $\&$ areal parts are reported to contain a wide range of active principles having medicinal values (Jaglan et al., 2013). The polypeptide isolated from this plant yield cystine, glutamic acid, phenyl alanine, tyrosine \& methionine on hydrolysis. Nicotine and nicotinic acid are reported to occur in this plant (Jadhav et al., 2009).

It is an active ingredient of many herbal formulations prescribed for liver ailments and shows effects on liver cell generation. It is used as a tonic and diuretic in hepatic and spleen enlargement (Jaglan et al., 2013). The main active principles of E. alba are wedelolactone and demethylwedelolactone, both of which possess anti hepatotoxic

1 Bangladesh Atomic Energy Commission, E-12/A, Sher-e-Bangla Nagar, Dhaka-1207, Bangladesh

*Corresponding author. E-mail: sabinanib79@gmail.com 
activity (Wagner et al., 1986 and Franca et al., 1995). It is also used in catarrhal jaundice and for skin diseases. It is commonly used in viral hepatitis to promote bile flow and protect the parenchyma and popularly used to enhance memory and learning (Banji, et al., 2007). Eclipta alba is a source of coumestan-type compounds used in phytopharmaceutical formulations of medicines prescribed for treatment of cirrhosis of the liver and infectious hepatitis (Wagner et al., 1986).

Externally it is used for inflammation, minor cuts and burns and the fresh leaf-juice is considered very effective in stopping bleeding. Leaf juice mixed with honey is also used for children with upper respiratory infections and also used in eye and ear infections (Jaglan et al., 2013).

The alcoholic extract of the plant has shown antiviral activity against Ranikhet disease virus (Dalal et al., 2010). The fresh juice of leaves is used for increasing appetite, improving digestion (Lans, 2007) and as a mild bowel regulator. The plant is traditionally used in hair oil for healthy black and long hair (Roy et al., 2008). The plant has a reputation as an anti-aging agent in Ayurveda (Thakur \& Mengi, 2005).

In recent years, the harvest of medicinal plants on a mass scale from their natural habitats is leading to a depletion of plant resources. The biodiversity of our country is decreased for over population and civilization. There has been an increased interest in in vitro culture techniques which offer a viable tool for mass multiplication and germplasm conservation of rare, endangered and threatened medicinal plants (Ajith Kumar \& Seeni, 1998, Prakash et al.1999). Therefore, it is important to develop an efficient micropropagation technique for Eclipta alba for rapid multiplication. In Bangladesh there have been a few reports on the establishment of micropropagation protocol for Eclipta alba (Hasan et al., 2008). In Bangladesh Hasan et al. (2008) developed a protocol for mass clonal propagation of this important medicinal harb using apical and axillary buds with survival rate $80 \%$ at outdoor condition. The present study aims at developing a simple, rapid, low-cost effective and high frequency regeneration protocol from nodal explants with higher survival rate so as to give rise to true-to-type clones for potential application in large- scale propagation.

\section{MATERIALS AND METHODS}

The experiments were carried out in the Plant Biotechnology Division of National Institute of Biotechnology, Bangladesh. Eclipta alba was collected from the National Institute of Biotechnology campus. Nodal segments were used for this purpose. The nodal segments $(1.0-1.5 \mathrm{~cm})$ were excised and thoroughly washed under running tap water for 30 minutes. Then they were treated with mild detergent followed by rinsing several times with autoclaved distilled water. The explants were dipped in $0.5 \%$ antifungal bavistin for 10 mins and again washed 4-5 times with sterilized distilled water. Further sterilization was done in laminar air flow cabinet under aseptic conditions. The explants were dipped in $70 \%(\mathrm{v} / \mathrm{v})$ ethanol for 1.0 minute and then washed three times with sterilized distilled water. For surface sterilization, the explants were dipped in $0.1 \%$ aqueous solution (w/v) 
of $\mathrm{HgCl}_{2}$ for 2-3 minutes. Finally they were washed in sterilized distilled water for 3-4 times, till the sterilents were removed completely. The nodal segments were then trimmed/cut at both ends prior to inoculation on culture media. The explants were cultured on MS (Murashige and Skoog, 1962) medium with 3\% sucrose and supplemented with different concentrations of cytokinins BAP and $\mathrm{Kn}(0.5-3.0 \mathrm{mg} / \mathrm{l})$ alone or in combination with auxins NAA and IAA $(0.1-0.5 \mathrm{mg} / \mathrm{l})$. The $\mathrm{pH}$ of the medium was adjusted to 5.8 by adding $1 \mathrm{~N} \mathrm{NaOH} / 1 \mathrm{~N} \mathrm{HCl}$ before the addition of agar. The medium was gelled with $0.8 \%$ agar and autoclaved at $121^{\circ} \mathrm{C}$ for 20 minutes.

After inoculation, all the cultures were incubated at $28 \pm 2^{\circ} \mathrm{C}$ temperature and $16 / 8$ (light/dark) photoperiod with 3000 lux intensity illumination provided by cool-white fluorescent tubes. After three-four weeks the explants were subcultured at a regular interval of 10-15 days.

For root induction 3-4 $\mathrm{cm}$ long shoots were cut and transferred to half and full strength MS medium fortified with auxins IAA, IBA and NAA (0.1-0.3 mg/l) singly. The rooted plantlets were taken out from the culture vessels and rinsed with sterilized distilled water to remove all trace of medium attached to the roots. After washing, plantlets were transplanted in small plastic pots containing autoclaved garden soil and compost (1:1). In order to maintain a high humidity the pots were then covered with transparent polythene bags and acclimatized in the growth room temperature $\left(28 \pm 2^{\circ} \mathrm{C}\right)$ for 3 weeks. After 2-3 weeks, these pots were uncovered and then they were exposed to partial and then complete direct sun light. Finally, these hardened plantlets were transferred to the natural condition for their further growth and development.

\section{RESULTS AND DISCUSSION}

In the present study nodal segments were used as explants. There are a lot of reports on nodal segments used as explants in other medicinal plants (Biswas et at., 2009, Hassan \& Roy 2004, Sultana \& Handique, 2004, Jain et al., 2003, Chandramu et al., 2003). Nodal segments were inoculated on MS medium supplemented with different concentrations of BAP $(0.5-3.0 \mathrm{mg} / \mathrm{l})$ and $\mathrm{Kn}(0.5-3.0 \mathrm{mg} / \mathrm{l})$ separately or in combinations with low concentrations of NAA $(0.1-0.5 \mathrm{mg} / \mathrm{l})$ and IAA $(0.1-0.5 \mathrm{mg} / \mathrm{l})$. Results of these experiments were presented in Table $1 \& 2$. In case of BAP the maximum number of shoots were obtained in MS medium supplemented with $1.0 \mathrm{mg} / 1$ BAP. In this concentration $76.66 \%$ explants responded for shoot induction and the maximum number $(8.4 \pm 0.62)$ of shoots per explants, highest shoot length $(4.23 \pm 0.26)$ as well as maximum number $(6.80 \pm 0.51)$ of leaves per shoots were recorded (Table 1). This result was not similar with earlier report (Sharma et al. 2013) where 15-17 shoots/explants in $1.0 \mathrm{mg} / \mathrm{l}$ BAP were induced. Gawda \& Paratkar (2004) reported 10-12 shoots per explant in 4.44 $\mu M$ BA. Dhaka \& Kothari (2005) also reported a highly efficient and reproducible protocol for $E$. alba through nodal explant on MS+1.0 mg/BAP. In the present investigation the initiation of multiple shoot formation was obtained within six to ten days and BAP showed better response to multiple shoot formation as compared to $\mathrm{Kn}$. This result corroborates with the results obtained by Baskaran \& Jayabalan (2003). But the length of shoot and internode, thickness of stem and leaf size is higher in Kn than BAP. 
The maximum number $(6.50 \pm 0.5)$ of shoots per explants with an average length (4.05 \pm 0.20$)$ of shoot and average number of leaves $(7.70 \pm 0.40)$ were found in $1.0 \mathrm{mg} / \mathrm{l}$ $\mathrm{Kn}$. In the present study the number of shoots were decreased and showed bushy structure with the increase of cytokinins (BAP and $\mathrm{Kn}$ ) which is similar with the results of $\mathrm{Hu} \&$ Wang (1983).

Table 1. Effects of BAP and Kn singly on multiple shoot regeneration from nodal segments of E. alba

\begin{tabular}{c|c|c|c|c|c}
\hline \multicolumn{2}{c|}{$\begin{array}{c}\text { Growth regulators } \\
(\mathrm{mg} / \mathrm{l})\end{array}$} & $\begin{array}{c}\text { Explants inducing } \\
\text { shoots }(\%)\end{array}$ & $\begin{array}{c}\text { Number of } \\
\text { shoots/explants }\end{array}$ & $\begin{array}{c}\text { Shoot length } \\
(\mathrm{cm})\end{array}$ & $\begin{array}{c}\text { Number of } \\
\text { leaves/shoots }\end{array}$ \\
\hline BAP & Kn & Mean & Mean \pm SE & Mean \pm SE & Mean \pm SE \\
\hline 0.5 & & 66.66 & $4.40 \pm 0.34$ & $3.86 \pm 0.21$ & $6.30 \pm 0.30$ \\
1.0 & & 76.66 & $8.40 \pm 0.62$ & $4.23 \pm 0.26$ & $6.80 \pm 0.51$ \\
1.5 & 70.00 & $5.20 \pm 0.49$ & $4.09 \pm 0.26$ & $6.50 \pm 0.31$ \\
2.0 & 65.00 & $5.60 \pm 0.48$ & $4.00 \pm 0.27$ & $6.20 \pm 0.36$ \\
2.5 & & 60.00 & $5.10 \pm 0.53$ & $3.13 \pm 0.13$ & $6.00 \pm 0.26$ \\
3.0 & & 60.00 & $4.70 \pm 0.42$ & $3.24 \pm 0.11$ & $6.30 \pm 0.30$ \\
& 0.5 & 45 & $5.80 \pm 0.42$ & $3.26 \pm 0.15$ & $6.50 \pm 0.34$ \\
& 1.0 & 68.66 & $6.50 \pm 0.50$ & $4.05 \pm 0.20$ & $7.70 \pm 0.40$ \\
& 1.5 & 66.66 & $4.70 \pm 0.45$ & $3.71 \pm 0.23$ & $7.20 \pm 0.49$ \\
& 2.0 & 60 & $4.50 \pm 0.34$ & $3.50 \pm 0.24$ & $6.80 \pm 0.36$ \\
& 2.5 & 55 & $4.10 \pm 0.28$ & $3.98 \pm 0.21$ & $6.30 \pm 0.30$ \\
& 3.0 & 50 & $4.00 \pm 0.37$ & $3.45 \pm 0.22$ & $6.20 \pm 0.33$ \\
\hline
\end{tabular}

Results are mean \pm SE of 15 replications.

Data recorded after eight weeks of culture.

Table 2. Effects of different concentrations and combinations of BAP, NAA and IAA on shoot induction

\begin{tabular}{c|c|c|c|c|c|c}
\hline \multicolumn{2}{l|}{ Growth regulators (mg/l) } & \begin{tabular}{c} 
Explants \\
inducing \\
\multicolumn{2}{l|}{}
\end{tabular} & $\begin{array}{c}\text { Number of } \\
\text { shoots/explants }(\%)\end{array}$ & $\begin{array}{c}\text { Shoot } \\
\text { length }(\mathrm{cm})\end{array}$ & $\begin{array}{c}\text { Number of } \\
\text { leaves/shoots }\end{array}$ \\
\hline BAP & NAA & IAA & Mean & Mean \pm SE & Mean \pm SE & Mean \pm SE \\
\hline 1.0 & 0.1 & & 90 & $18.40 \pm 0.67$ & $4.50 \pm 0.31$ & $8.50 \pm 0.37$ \\
1.0 & 0.2 & & 83.33 & $12.5 \pm 0.96$ & $4.09 \pm 0.27$ & $8.10 \pm 0.41$ \\
1.0 & 0.3 & & 75 & $8.10 \pm 0.48$ & $4.00 \pm 0.27$ & $7.20 \pm 0.29$ \\
1.0 & 0.5 & & 70 & $7.70 \pm 0.50$ & $3.99 \pm 0.16$ & $7.20 \pm 0.33$ \\
1.0 & & 0.1 & 73.33 & $9.50 \pm 0.70$ & $4.09 \pm 0.22$ & $8.10 \pm 0.41$ \\
1.0 & 0.2 & 66.66 & $7.10 \pm 0.43$ & $3.97 \pm 0.16$ & $7.20 \pm 0.36$ \\
1.0 & 0.3 & 60.00 & $6.50 \pm 0.34$ & $3.90 \pm 0.23$ & $7.10 \pm 0.28$ \\
1.0 & & 0.5 & 60 & $5.20 \pm 0.42$ & $3.74 \pm 0.17$ & $6.80 \pm 0.33$ \\
\hline
\end{tabular}

Results are mean $\pm \mathrm{SE}$ of 15 replications.

Data recorded after eight weeks of culture.

Multiple shoot regeneration from E. alba nodal explants cultured on MS media supplemented with various concentrations and combinations of BAP, NAA and IAA were studied. The effect of BAP in combination with an auxin has been reported and in most of the cases BAP and NAA were used for the induction of multiple shoots of various medicinal plants (Sudha et al., 1998, Huang et al., 2000, Chen et al., 2001, Biswas et at., 
2009). The percentage of responded explants, number of shoots per explants, number of leaves, length of shoots and proliferation of shoots differed with the medium constituents. In the present study, among the four different media used the nodal explants in MS medium supplemented with $1.0 \mathrm{mg} / \mathrm{l}$ BAP and $0.1 \mathrm{mg} / \mathrm{l}$ NAA grew vigorously. The explants (nodal segments) started in producing shoots within one week in MS medium supplemented with BAP and NAA (Plate 1). The highest percentage of responsive explants (90\%) was examined in $\mathrm{MS}+1.0 \mathrm{mg} / \mathrm{l} \mathrm{BAP}+0.1 \mathrm{mg} / \mathrm{l} \mathrm{NAA}$. The maximum number $(18.40 \pm 0.67)$ of shoots per explants, shoot length $(4.50 \pm 0.31)$ and average number $(8.50 \pm 0.37)$ of leaves were found in this medium. Sharma et al (2013) also reported that MS medium supplemented with $1.0 \mathrm{mg} / \mathrm{l} \mathrm{BAP}$ and $0.1 \mathrm{mg} / \mathrm{l} \mathrm{NAA}$ was most effective for shoot induction in E. alba. In the present study it was observed that explants with small shoots were subcultured in the same medium the number of multiple shoots were increased but the shoot length, leaves size and chlorophyll content were decreased. Repeated subculture in the same medium at 8-10 day intervals resulted profuse shoot multiplication (Plate 2). For shoot elongation and proliferation, the regenerated multiple shoots were transferred into MS medium supplemented with $1.0 \mathrm{mg} / \mathrm{l} \mathrm{BAP}$ (Plate 3 \& 4). These shoots were further multiplied and maintained in same media (MS+1.0mg/l BAP) for further shoot multiplication. Almost similar results were also reported by Dhaka and Kothari (2005) and Gawda \& Paratkar (2004). Combination of BAP with IAA was not found suitable for multiple shoot induction. This is identical with the results obtained by Hassan et al., 2008 using apical and axillary bud. The maximum number $(9.50 \pm 0.70)$ of shoot induction was found in MS $+1.0 \mathrm{mg} / 1 \mathrm{BAP}+0.1 \mathrm{mg} / \mathrm{IAA}$.

Table 3. Effects of IBA, IAA and NAA on in vitro root induction in regenerated shoots of Eclipta alba on half and full strength MS

\begin{tabular}{|c|c|c|c|c|c|c|c|}
\hline \multirow[t]{2}{*}{$\begin{array}{c}\text { MS } \\
\text { strength }\end{array}$} & \multicolumn{2}{|c|}{$\begin{array}{c}\text { Growth } \\
\text { regulators }(\mathrm{mg} / \mathrm{l})\end{array}$} & \multirow[b]{2}{*}{ NAA } & \multirow{2}{*}{$\begin{array}{c}\text { Rooted } \\
\text { shoots } \\
(\%)\end{array}$} & \multirow[t]{2}{*}{$\begin{array}{l}\text { Days required } \\
\text { for rooting }\end{array}$} & \multirow[t]{2}{*}{$\begin{array}{l}\text { No. of roots/ } \\
\text { shoot }\end{array}$} & \multirow[t]{2}{*}{$\begin{array}{l}\text { Length of } \\
\text { roots }(\mathrm{cm})\end{array}$} \\
\hline & IBA & IAA & & & & & \\
\hline $1 / 2 \mathrm{MS}$ & 0.1 & & & 96 & $15-16$ & $8.70 \pm 0.42$ & $4.64 \pm 0.23$ \\
\hline $1 / 2 \mathrm{MS}$ & 0.2 & & & 90 & $18-20$ & $7.10 \pm 0.43$ & $3.96 \pm 0.17$ \\
\hline $1 / 2 \mathrm{MS}$ & 0.3 & & & 70 & $20-22$ & $6.60 \pm 0.45$ & $3.31 \pm 0.16$ \\
\hline $1 / 2 \mathrm{MS}$ & & 0.1 & & 84 & 20 & $8.60 \pm 0.45$ & $3.99 \pm 0.28$ \\
\hline $1 / 2 \mathrm{MS}$ & & 0.2 & & 78 & $17-18$ & $7.70 \pm 0.37$ & $3.51 \pm 0.18$ \\
\hline $1 / 2 \mathrm{MS}$ & & 0.3 & & 65 & $21-22$ & $6.60 \pm 0.37$ & $3.55 \pm 0.17$ \\
\hline $1 / 2 \mathrm{MS}$ & & & 0.1 & 55 & $19-20$ & $7.00 \pm 0.26$ & $4.12 \pm 0.26$ \\
\hline $1 / 2 \mathrm{MS}$ & & & 0.2 & 42 & $22-23$ & $6.20 \pm 0.25$ & $3.93 \pm 0.18$ \\
\hline $1 / 2 \mathrm{MS}$ & & & 0.3 & 45 & $22-123$ & $6.00 \pm 0.30$ & $3.29 \pm 0.16$ \\
\hline MS & 0.1 & & & 90 & $16-17$ & $8.50 \pm 0.34$ & $4.53 \pm 0.26$ \\
\hline MS & 0.2 & & & 88 & 22 & $7.50 \pm 0.34$ & $4.08 \pm 0.19$ \\
\hline MS & 0.3 & & & 65 & 21 & $5.90 \pm 0.38$ & $3.80 \pm 0.23$ \\
\hline MS & & 0.1 & & 66 & $19-20$ & $8.20 \pm 0.47$ & $4.67 \pm 0.30$ \\
\hline MS & & 0.2 & & 60 & $16-17$ & $5.50 \pm 0.34$ & $4.05 \pm 0.25$ \\
\hline MS & & 0.3 & & 55 & $18-20$ & $6.80 \pm 0.47$ & $4.09 \pm 0.25$ \\
\hline MS & & & 0.1 & 50 & 24 & $6.00 \pm 0.42$ & $4.15 \pm 0.21$ \\
\hline MS & & & 0.2 & 45 & 23 & $6.20 \pm 0.33$ & $3.92 \pm 0.25$ \\
\hline MS & & & 0.3 & 40 & $25-26$ & $5.30 \pm 0.30$ & $3.78 \pm 0.22$ \\
\hline
\end{tabular}

Results are mean \pm SE of 15 replications.

Data recorded after four weeks of culture. 

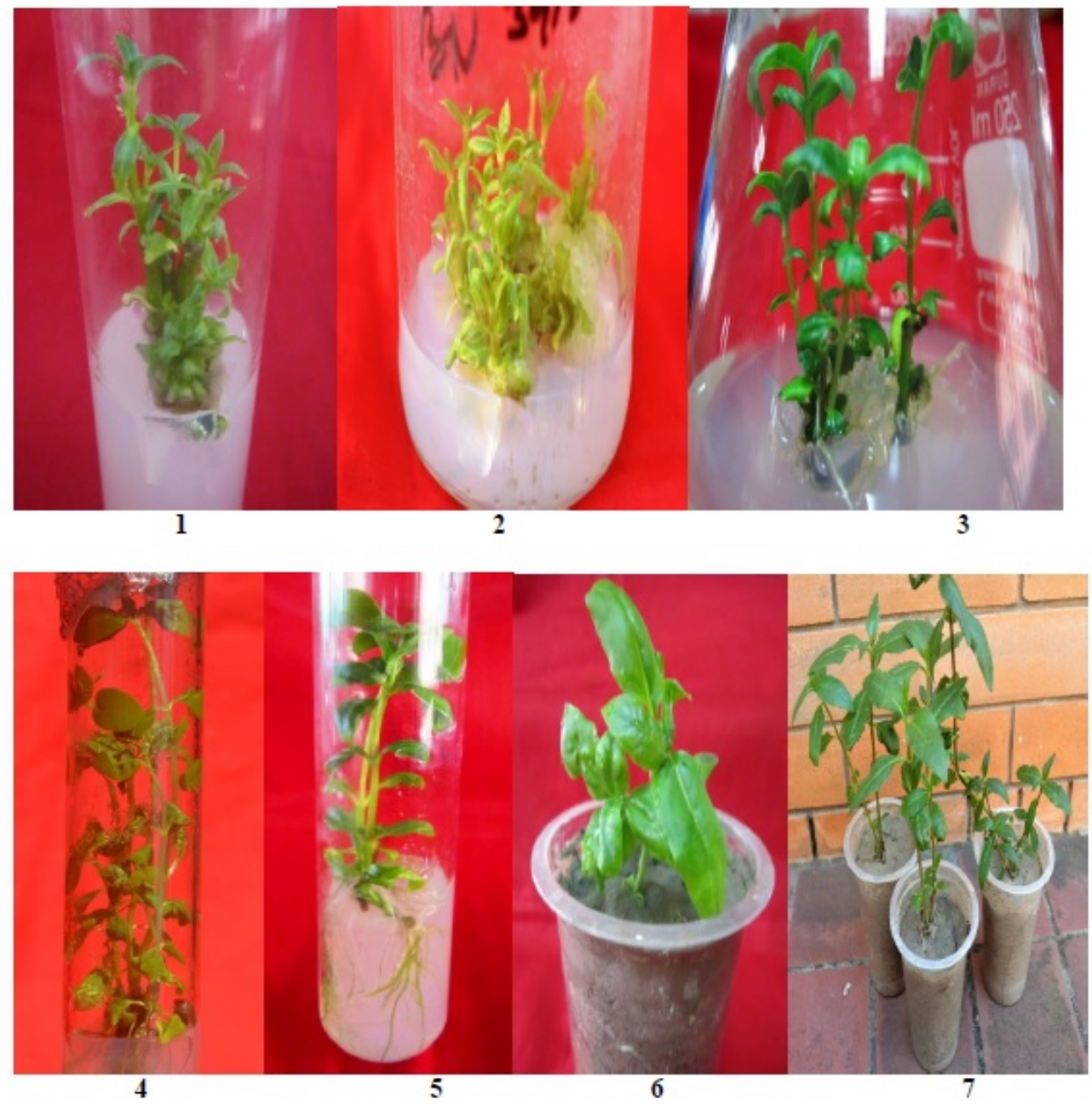

Plate 1-7. In vitro regeneration of Eclipta alba (L.) Hassk. from nodal segment explants. 1. Induction of multiple shoots on $\mathrm{MS}+1.0 \mathrm{mg} / \mathrm{l} \mathrm{BAP}+0.1 \mathrm{mg} / \mathrm{l} \mathrm{NAA}$ after three weeks of culture; 2 . Development and multiplication of shoots in same medium. 3 \& 4. Elongation and proliferation of in vitro shoots on $\mathrm{MS}+1.0 \mathrm{mg} / \mathrm{l} \mathrm{BAP;} 5$. Rooting of in vitro regenerated shoots on half MS $+0.1 \mathrm{mg} / \mathrm{l} \mathrm{IBA;} 6$. Acclimatization of in vitro grown plantlets in small plastic pots. 7. Fully acclimatized regenerated plants in open air after five weeks of transplantation

The regenerated multiple shoots, obtained from MS $+1.0 \mathrm{mg} / \mathrm{l} \mathrm{BAP}$ and $0.1 \mathrm{mg} / \mathrm{l} \mathrm{NAA}$, when subcultured on $\mathrm{MS}+1.0 \mathrm{mg} / \mathrm{l} \mathrm{BAP}$ for elongation and proliferation produced rooting simultaneously. But those were found to be inadequate for transplantation and therefore adequate root induction is necessary. 
For induction of roots regenerated healthy shoots of 3-4 $\mathrm{cm}$ length were excised and cultured on half and full strength of MS medium supplemented with different concentrations $(0.1-0.3 \mathrm{mg} / \mathrm{l})$ of IBA, IAA $(0.1-0.3 \mathrm{mg} / \mathrm{l})$ and NAA $(0.1-0.3 \mathrm{mg} / \mathrm{l})$ singly. The results of these experiments are presented in Table 3. Use of auxins singly or in combination for rooting in E. alba were also reported by different authors (Hassan et al., 2008, Baskaran \& Jayabalan, 2003, Sharma et al., 2013). Among the different auxins (IBA, IAA and NAA) the best root induction and development was found in half strength MS medium containing $0.1 \mathrm{mg} / \mathrm{l}$ IBA. The highest percentage $(96 \%)$ of root formation, maximum number of roots $(8.70 \pm 0.42)$ and highest length $(4.64 \pm 0.23)$ of roots were recorded in this medium within three weeks of inoculation (Plate 5). Several earlier researchers (Khalekuzzaman et al., 2008, Biwas et al., 2009, Hassan et al., 2010, Das et al., 2008, Karthikeyan et al., 2009) reported root induction in different medicinal plants by using IBA in MS and modified MS. In the present study it was observed that IAA and NAA were less effective for root induction in E. alba.

After sufficient development of roots the plantlets were transferred into small plastic pots containing soil and compost (Plate 6). Following proper acclimatization, plantlets were transferred to open air and $95 \%$ plants survived (Plate 7). 300 plantlets were transferred into experimental field and among them $90 \%$ plants survived. The in vitro regenerated plants grew vigorously in field condition and they did not show any morphological variation. These plantlets flowered within 45 days after transplantation and set seeds. Sharma et al. (2013), Hasan et al. (2008), Ragavendran et al. (2014), and Borthakur et al. (2000) reported 35\%, 80\%, 70\%, and 50\% survival rate respectively. The in vitro regeneration protocol developed here is cost effective, rapid and reproducible. This protocol can be applied for large scale clonal propagation and conservation of this elite medicinal plant species.

\section{REFERENCES}

Ajitkumar, D. and Seeni, S. 1998. Rapid clonal multiplication through in vitro axillary shoot proliferation of Aegel marmelos (L.) Corr., a medicinal tree. Plant Cell Rep. 17: 422-426.

Baskaran, P. and Jayabalan, N. 2003. An efficient micropropagation system for Eclipta alba - a valuable medicinal herb. In vitro cell. Dev. Biol. Plant 41: 532-539.

Biswas, A., Bari, M. A., Roy, M. and Bhadra, S.K. 2009. Clonal propagation through nodal explant culture of Boerhaavia diffusa L.-A rare medicinal plant. Plant tissue cult. \& Biotech. 19(1): 53-59.

Borthakur, M., Dutta, K., Nath, S. C. \& Singh, R. S. 2000. Micropropagation of Eclipta alba and Eupatorium adenophorum using a single-step nodal cutting technique. Plant Cell, Tissue and Organ Culture 62: 239-242.

Banji, O., Banji. DAnnamalai, A. and Manavalan, R. 2007. Investigation on the effect of Eclipta alba on animal models of learning and memory. Indian J physiol pharmacol. 51 (3): 274278.

Chandramu, C. Rao, D. M. and Reddy, V. D. 2003. High frequency induction of multiple shoots from nodal explants of Vitex negundu L. using sodium sulphate. J. Plant Biotechnol. 5 (2): 107-113. 
Chen, C.C., Chen, S. J., Sagare, A. P and Tsay, H. S. 2001. Adventitious shoot regeneration from stem internode explants of Adenophora triphylla (Thumb.) A. DC (Campanulaceae) - An important medicinal herb. Bot. Bull. Acad.Sin. 42:1-7.

Das, R., Hasan, M. F., Hossain, M.S and Rahman, M. 2008 Micropropagation of Centella asiatica L. an important medicinal herb. Progress. Agric. 19 (2): 51- 56.

Dalal, S., Kataria, K. S., Sastry, K. and Rana, S.V.S. 2010 Phytochemical screening of methanolic extract and antibacterial activity of active principles of hepatoprotective herb, Eclipta alba. Ethnobotanical leaflets. 14: 248-58.

Dhaka, N. and Kothari, S. L. 2005. Micropropagation of Eclipta alba (L.) Hassk- an important medicinal plant. In vitro cell Dev Biol. 41: 658-661.

Franca, S. C., Bertoni, B. W. and Pereira, A. M. S 1995. Antihepatotoxic agent in micropropagated plantlets of Eclipta alba. Plant Cell Tiss. Org. Cult. 40: 297-299.

Gawde, A. J. and Paratkar, G. T. 2004. Micropropagation of Eclipta alba Hassk.: An approach to shorten the protocol. Indian Journal of Biotechnology. 3: 128-132.

Hassan, A. K. M. S., Afroz, F., Bari, L. S., Munshi, J. L., Jahan, M. A. A and Khatun, R. (2008) Micropropagation of Eclipta alba (Linn.) Hassk- a Valuable Medicinal Herb. Bangladeh J. Sci. Ind. Res. 43 (2), 215-222.

Hassan, A. K. M. S. and Roy, S.K. 2004. Micropropagation of Smilex zeylanica L., a perennial climbing medicinal shrub, through axillary shoot proliferation. Bangladesh J. Life Sci. 6 (1): 33-39.

Hassan, A. K. M. S., Sultana, R., Jahan, M. A. A. and Khatun, R. 2010. In vitro mass propagation of Mimosa pudica L. using shoot tip and nodal explant. Bangladesh J. Sci. Ind. Res. 45 (2), 95- 100.

Hu, C.Y. and Wang. P.J. 1983. Meristem shoot tip and bud culture. In: Evans. D. A., Sharp, W. R, Ammirato, P. V., and Ymada, Y., (eds). Handbook of plant cell culture, pp. 177-227, Mac Millan \& Co., New York.

Huang, C. L., Hsieh, M. T., Hsieh, W. C., Sagare, A.P., and Tsay, H. S. 2000. In vitro propagation of Limonium wrightii (Hance) Ktze. (Plumbaginaceae), an ethnobotanical plant, from shoottip, leaf and inflorescence node explants. In Vitro Cell. Dev. Biol. Plant 36: 220-224.

Jadhav, V. M., Thorat, R. M. Kadam, V. J. and salakar, K. P. 2009. Chemical composition, pharmacological activities of Eclipta alba. J. of Pharm Res. 8: 112-123.

Jaglan, D., Brar, A. S. and Gill, R. 2013. Pharmacological activity and chemical constituents of Eclipta alba. Global journal of medical research 13 (1): 35- 40.

Jain, V., Singh, D., saraf, S. and Saraf, S. 2003. In vitro micropropagation of Rauwolfia serpemtina through multiple shoot generation. Ancient Science of life 23 (1): 44-49.

Karthikeyan, K. Chandran, C. and Kulothungan, S. 2009. Rapid clonal multiplication through in vitro axillary shoot proliferation of Centella asiatica L. Indian Journal of Biotechnology 8 : 232-235.

Khalekuzzaman, M., Rahman, M. S., Rashid, M. H. and Hossain, M.S. 2008. High frequency in vitro propagation of Adhatoda vesica Nees through shoot tip and nodal explants culture. $J$. bio-sci. 16: 35-39.

Lans, C. 2007. Comparison of plants used for skin and stomach problems in Trinidad and Tobago with Asian ethnomedicine. Journal of Ethnobiology and Ethnomedicine 3 (3): 1-12.

Murashige, T and Skoog, F 1962. A revised medium for rapid growth and bioassays with tobacco tissue cultures. Physiol. Plant 15: 473-497.

Prakash, E., Khan S. V. P. S, Reddy, S. P. and Rao, K. R. 1999. Regeneration of plants from seedderived callus of Hybanthus enneaspermus L. Muell., a rare ethnobotanical herb. Plant Cell Rep. 18: 873-878.

Roy, R. K., Thakur, M., Dixit, V. K. 2008. Hair growth promoting activity of Eclipta alba in male albino rats. Arch Dermatol Res. 300: 357-364. 
Ragavendran, C., Kamalanathan, D. and Natarajan, D. 2014. A Rapid Micropropagation of nodal explants of Eclipta alba (L.); A Multipurpose Medicinal Herb. Research in Biotechnology 5(2): 06-12.

Sharma, A., Bhansali, S. and Kumar, A. 2013. Micropropagation of Eclipta alba (L.) Hassk. An important medicinal plant of traditional medicine. ISSN 2250-0480, Vol 3/Issue 2

Sultana, S. and Handique, P.J. 2004. Micropropagation of Wedelia chinensis through high frequency shoot multiplication using nodal explants. J. Curr. Sci. 5: 447-452.

Sudha, C. G., Krishnan, P. N and Pushpangadan, P. 1998. In vitro propagation of Holostemma annulare (Roxb.) K. Schum., a rare medicinal plant. In Vitro Cell. Dev. Biol. Pl. 33: 57- 63.

Thakur, V. D. and Mengi, S. A. 2005. Neuropharmacological profile of Eclipta alba (Linn) Hassk. Journal of Ethnopharmacology; 102: 23-31.

Wagner, H., Geyer, B., Kiso, Y. and Rao, G. S. 1986. Coumestans as the main active principles of the liver drugs Eclipta alba and Wedelia calendulaceae. Planta med. 52: 370-373. 